\title{
Electrospinning pectin-based nanofibers: a parametric and cross-linker study
}

\author{
Devon McCune ${ }^{1} \cdot$ Xiaoru Guo ${ }^{2} \cdot$ Tong Shi $^{3} \cdot$ Samuel Stealey $^{1} \cdot$ Romare Antrobus $^{4} \cdot$ Matey Kaltchev $^{1}$ - Junhong Chen ${ }^{2}$. \\ Subha Kumpaty ${ }^{5}$. Xiaolin Hua ${ }^{6}$. Weiping Ren $^{3}$. Wujie Zhang ${ }^{1} \odot$
}

Received: 30 July 2017 / Accepted: 19 December 2017 / Published online: 3 February 2018

○) Springer-Verlag GmbH Germany, part of Springer Nature 2018

\begin{abstract}
Pectin, a natural biopolymer mainly derived from citrus fruits and apple peels, shows excellent biodegradable and biocompatible properties. This study investigated the electrospinning of pectin-based nanofibers. The parameters, pectin:PEO (polyethylene oxide) ratio, surfactant concentration, voltage, and flow rate, were studied to optimize the electrospinning process for generating the pectin-based nanofibers. Oligochitosan, as a novel and nonionic cross-liker of pectin, was also researched. Nanofibers were characterized by using AFM, SEM, and FTIR spectroscopy. The results showed that oligochitosan was preferred over $\mathrm{Ca}^{2+}$ because it cross-linked pectin molecules without negatively affecting the nanofiber morphology. Moreover, oligochitosan treatment produced a positive surface charge of nanofibers, determined by zeta potential measurement, which is desired for tissue engineering applications.
\end{abstract}

Keywords Pectin $\cdot$ Oligochitosan $\cdot$ Electrospinning $\cdot$ Nanofiber $\cdot$ Tissue engineering

\section{Introduction}

Tissue engineering shows promise for closing the gap between the number of people waiting for an organ transplant and the number of people receiving one by restoring

Electronic supplementary material The online version of this article (https://doi.org/10.1007/s13204-018-0649-4) contains supplementary material, which is available to authorized users.

Wujie Zhang

zhang@msoe.edu

1 BioMolecular Engineering Program, Department of Physics and Chemistry, Milwaukee School of Engineering, $1025 \mathrm{~N}$ Broadway, Milwaukee, WI 53202, USA

2 Department of Mechanical Engineering, University of Wisconsin-Milwaukee, Milwaukee, WI 53201, USA

3 Department of Biomedical Engineering, Wayne State University, Detroit, MI 48201, USA

4 Department of Biochemistry, Lawrence University, Appleton, WI 54911, USA

5 Department of Mechanical Engineering, Milwaukee School of Engineering, Milwaukee, WI 53202, USA

6 Deptartment of Obstetrics and Gynecology, Xinhua Hospital, Shanghai Jiao Tong University School of Medicine, Shanghai 200092, China the function of damaged tissue or replacing it altogether. In tissue engineering, the use of scaffolds allows cells to have the support necessary to grow and regenerate the extracellular matrix (ECM) (Hinderer et al. 2016; Naahidi et al. 2017). $\mathrm{ECM}$ is a complex $3 \mathrm{D}$ environment where tissue cells can proliferate and function. The matrix is composed of fiber forming proteins as well as collagen fibers and soluble factors (Hinderer et al. 2016). There is a great interest in fabricating scaffolds using nanofibers mimicking ECM for tissue engineering, considering the majority of the ECM biomolecules are at nanoscale and fibrous (Ao et al. 2017; Ingavle and Leach 2014; Limongi et al. 2016; Mortimer and Wright 2017; Ngadiman et al. 2017). Scaffolds with nanoscale architectures provide many more binding sites to cell membrane receptors, compared with micropore or microfiber scaffolds (Stevens and George 2005). Electrospinning is one of the most commonly used methods for fabricating nanofibers. The electrospinning process involves pumping a polymer solution through a syringe to form a droplet on the needle tip. When high voltage is applied, a cone shape (Taylor cone) is formed, followed by a thin stream of polymer solution. During the fly, the solvent evaporates leaving a solid fiber at the grounded collector (Agarwal et al. 2008; Babitha et al. 2017). 
Pectin is an anionic heteropolysaccharide found in the cell wall of all land plants (Noreen et al. 2017). Due to its biocompatibility and biodegradability, pectin has been used for various biological applications: including cell encapsulation, creating artificial red blood cells, bioprinting, and drug delivery (Banks et al. 2016; Crouse et al. 2015; Harvestine et al. 2014; Zhang et al. 2016a; Zhang et al. 2016b). Very recently, pectin has been explored for fabricating nanofibers. When electrospinning pectin alone, forming nanofibers remains challenging. A synthetic polymer such as poly(ethylene oxide) (PEO) or poly(vinyl alcohol) (PVA) is blended in with the pectin to improve its ability to be electrospun into fibers (2016, Cui et al. 2017). Moreover, cross-linking of pectin molecules within the nanofibers is essential to increase their stability in aqueous solutions. Since pectin is composed of galacturonic acid with carboxyl groups, divalent cations, such as $\mathrm{Ca}^{2+}$, can be used as cross-linkers (Cui et al. 2017). This is very similar to the polysaccharide alginate (Bonino et al. 2011; Feng et al. 2017). However, the divalent cations of the cross-linking agents can negatively influence cell viability and function (Harvestine et al. 2014). These cations also have tendencies to leak out of the target material, leading to loss of stability and functionality. In our previous studies, oligochitosan, a natural cationic oligosaccharide, was proven to be an effective nonionic cross-linker of pectin (Crouse et al. 2015; Harvestine et al. 2014; Zhang et al. 2016a; Zhang et al. 2016b). Oligochitosan and pectin have complementary charges leading to the formation of polyelectrolytes. Additionally, oligochitosan can potentially generate a positive surface charge of the nanofibers, due to its protonated amino groups (Zhang et al. 2013). This is critical for tissue engineering applications, since a positively charged surface is preferred for cell adhesion (Ko et al. 2015; Suga et al. 2015; Zhang et al. 2017). Overall, the goal of this research is to optimize the parameters for electrospinning of pectin-based nanofibers and explore the potential of using oligochitosan as a cross-linker.

\section{Materials and methods}

\section{Materials}

Low methyl (LM) pectin was purchased from Willpowder (Miami Beach, FL, USA). Pharmaceutical-grade oligochitosan (MW 2-3 kDa, > 90\% deacetylation) was obtained from Zhejiang Golden-Shell Pharmaceutical Co. Ltd (Zhejiang, China). Polyethylene oxide (PEO, $600 \mathrm{kD}$ ), Pluronic ${ }^{\circledR}$ F-127, and $\mathrm{CaCl}_{2}$ were purchased from Sigma Aldrich (St. Louis, MO, USA).

\section{Parameters Optimization of the Electrospinning Process}

The electrospinning setup (Linari Engineering, Valpiana, Italy) consisted of a syringe pump, $40 \mathrm{kV}$ high voltage generator, and a stationary plastic collector plate covered by aluminum foil. The distance between the blunt syringe needle tip (25 Gauge) and the collector plate was kept constant at $20 \mathrm{~cm}$. The solution preparation parameters studied include the pectin $(4 \%, \mathrm{w} / \mathrm{v})$ : PEO $(4 \%, \mathrm{w} / \mathrm{v})$ ratio (from $70: 30$ to 40:60), Pluronic ${ }^{\circledR} \mathrm{F}-127$ concentration (from $2 \%$ (w/v) to $10 \%(\mathrm{w} / \mathrm{v})$ ), flow rate (from 0.2 to $1.2 \mathrm{~mL} / \mathrm{h}$ ), and voltage (from 10 to $25 \mathrm{kV}$ ). The influence of each parameter was investigated by varying one of the parameters while keeping the other parameters constant. Nanofibers were electrospun directly onto mica discs attached to the aluminum foil. The discs with nanofiber samples were then examined under a Bruker MultiMode atomic force microscope (AFM) with the Nanoscope IIIa controller using the contact mode.

\section{Cross-linking of the pectin-based nanofibers}

Collected nanofibers were first soaked in $95 \%$ ethanol for $2 \mathrm{~min}$, followed either by a $150 \mathrm{mM}$ calcium solution or a $5 \%$ (w/v) oligochitosan solution for $2 \mathrm{~min}$. The nanofibers were then washed with DI water three times and oven dried before further analysis.

\section{Characterization of the pectin-based nanofibers}

Before scanning electron microscope (SEM) imaging was performed, the nanofiber samples were dried in a $35{ }^{\circ} \mathrm{C}$ oven, mounted onto an aluminum stub and sputter-coated with a $2 \mathrm{~nm}$ layer of iridium. Samples were then examined under a Hitachi S-4800 Ultra High Resolution Cold Cathode Field Emission Scanning Electron Microscope (FESEM). Dried nanofiber samples were also used for FTIR spectroscopy analysis using a NicoletTM 6700 spectrometer (Thermo Fisher Scientific). To measure the surface charge (represented by the surface zeta potential), nanofibers were dissolved/suspended in de-ionized (DI) water and their surface charge was measured using a Brookhaven (Holtsville, NY) zeta potential analyzer.

\section{Cell culture and cytotoxicity assay}

Mouse MC3T3-E1 preosteoblasts (ATCC; Manassas, VT) were plated at a density of $2.5 \times 10^{5}$ cells/well in a 24-well plate and cultured in $\alpha$-MEM (HyClone; Logan, UT) supplemented with $10 \%$ fetal bovine serum, $100 \mathrm{U} / \mathrm{mL}$ penicillin, and $100 \mu \mathrm{g} / \mathrm{mL}$ streptomycin at $37^{\circ} \mathrm{C}$ in a humidified, $5 \%$ 
$\mathrm{CO}_{2}$ incubator. The cell culture medium was then replaced with fresh culture medium supplemented with various nanofibers $(1 \mathrm{mg} / \mathrm{mL})$ for $24 \mathrm{~h}$ after cell seeding. Cell toxicity was determined by measuring the release of lactate dehydrogenase (LDH) from membrane integrity-compromised cells into the culture medium at different time points using a Cytotoxicity Detection Kit (Roche Diagnostics GmbH, Mannheim, Germany) following the manufacturer's instructions (Song et al. 2011). Briefly, $100 \mu \mathrm{L}$ of culture medium was added into a plate of 96 wells, mixed with $100 \mu \mathrm{L}$ working solution, and incubated at room temperature for $30 \mathrm{~min}$ in the dark. Then, the plate was read under the UVmax colorimeter (Molecular Devices, Sunnyvale, California) at optical density (OD) $490 \mathrm{~nm}$. Blank culture medium was used as a control.
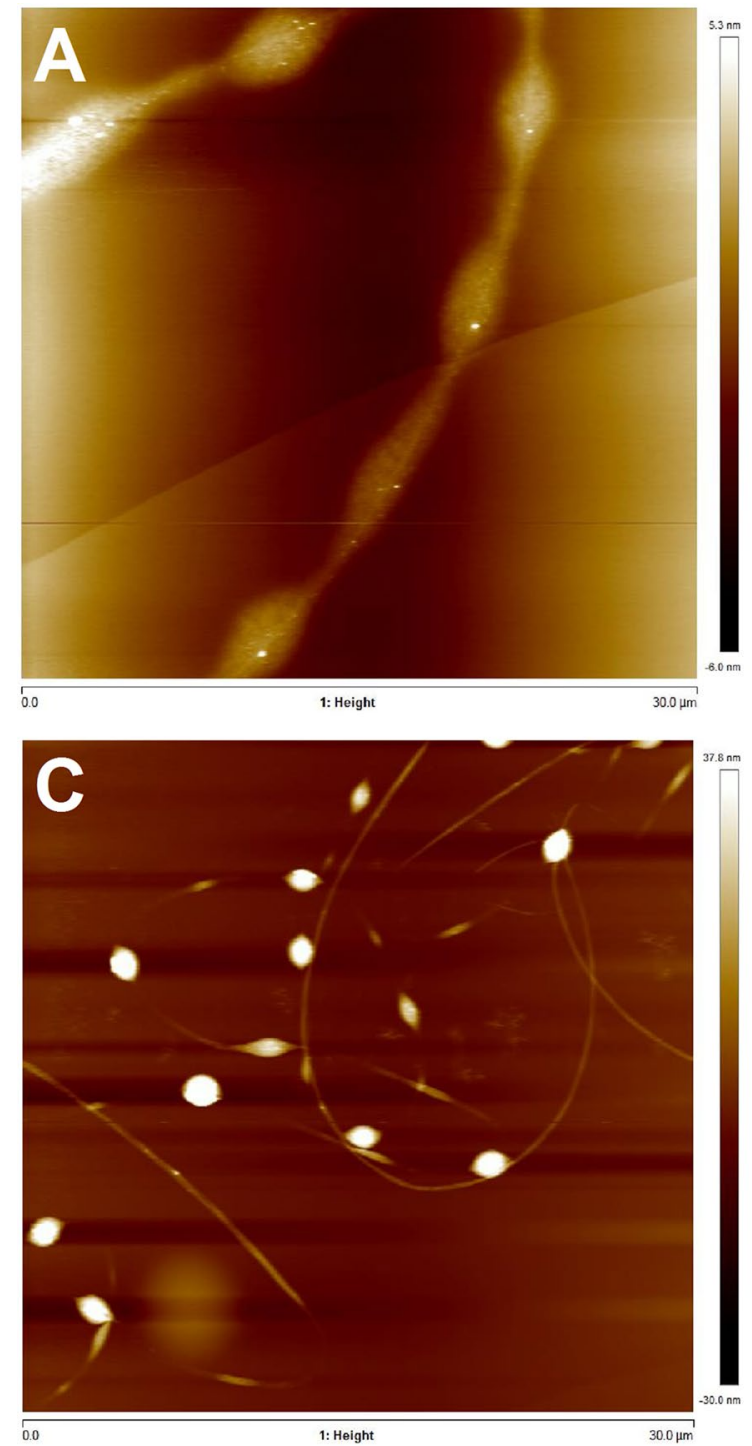

\section{Results and discussion}

\section{Effect of preparation parameters on the electrospinning process}

PEO was used as a synthetic carrier to improve the electrospinning ability of polymers (Bonino et al. 2011; Cui et al. 2016). First, different pectin:PEO ratios, 70:30, 60:40, 50:50, 40:60, and 30:70 (v/v), were tested to study the ratios' influence on the electrospinning process. It was found that no distinct nanofiber could be produced when the pectin's percentage was either too high (70:30) or too low (30:70) (Fig. 1a). When using the other ratios, 60:40, 50:50, and 40:60, nanofibers were produced, albeit with beads as shown in Fig. 1. Since the 60:40 ratio blend produced nanofibers
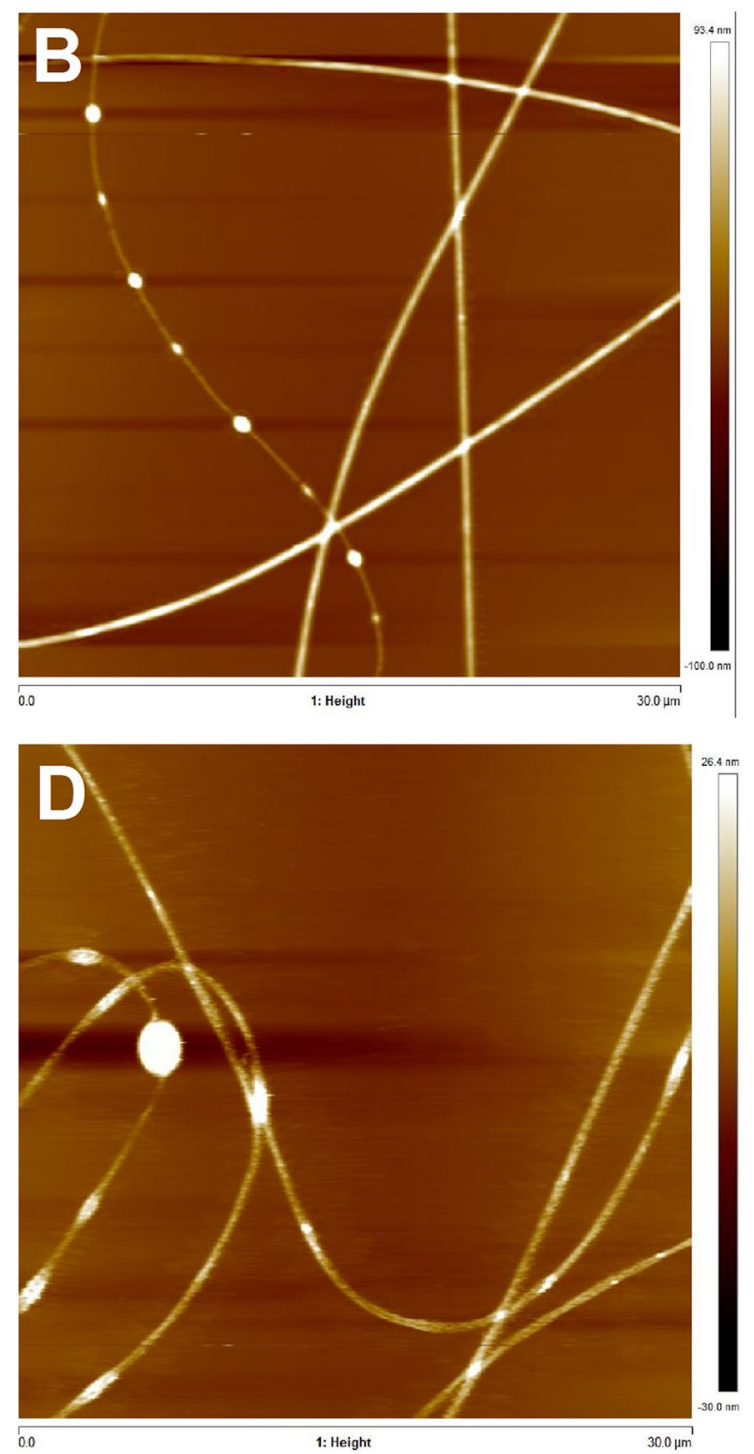

Fig. 1 AFM images of the nanofibers produced by various ratios of pectin: PEO. a 70:30, b 60:40, c 50:50, and d 40:60 
with the least amount of beads, a 65:35 ratio, with a slightly decreased PEO percentage, was used for the duration of the study.

It has been demonstrated that Pluronic ${ }^{\circledR}$ F-127 can be used as a nonionic surfactant to aid in the electrospinning process (Bonino et al. 2011). To eliminate the bead formation during the process, various Pluronic ${ }^{\circledR}$ F-127 concentrations of $2,5,7.5$, and $10 \%(\mathrm{w} / \mathrm{v})$ were investigated. At lower concentrations of Pluronic ${ }^{\circledR}$ F-127, the solution surface tension was too high which caused bead formation in the fibers. When the concentration of Pluronic ${ }^{\circledR}$ F-127 was increased to $5 \%$, uniform beadless nanofibers were successfully fabricated. However, no stable nanofibers were formed with further increase in the surfactant concentration. This is most likely due to the increasing concentration of the surfactant which reduced the surface tension of the resulting material to the point where fibers could not hold their physical structure.

During optimization of the flow rate, it was noticed that the 0.4 and $0.7 \mathrm{~mL} / \mathrm{h}$ settings led to the production of stable nanofibers with a smooth surface (Fig. 2b, c). When the flow rate was too low or too high, distinct nanofibers could either not be generated (Fig. 2a), or the surface morphology would not be optimized (Fig. 2d). Considering the production efficiency and general morphology, $0.7 \mathrm{~mL} / \mathrm{h}$ was chosen for the rest of the study.

Finally, the voltage was not found to influence the electrospinning process significantly within the range of $10-18 \mathrm{kV}$ (Fig. 3a-c). However, when the voltage exceeded $20 \mathrm{kV}$, nanofibers could not be detected (Fig. 3d). The
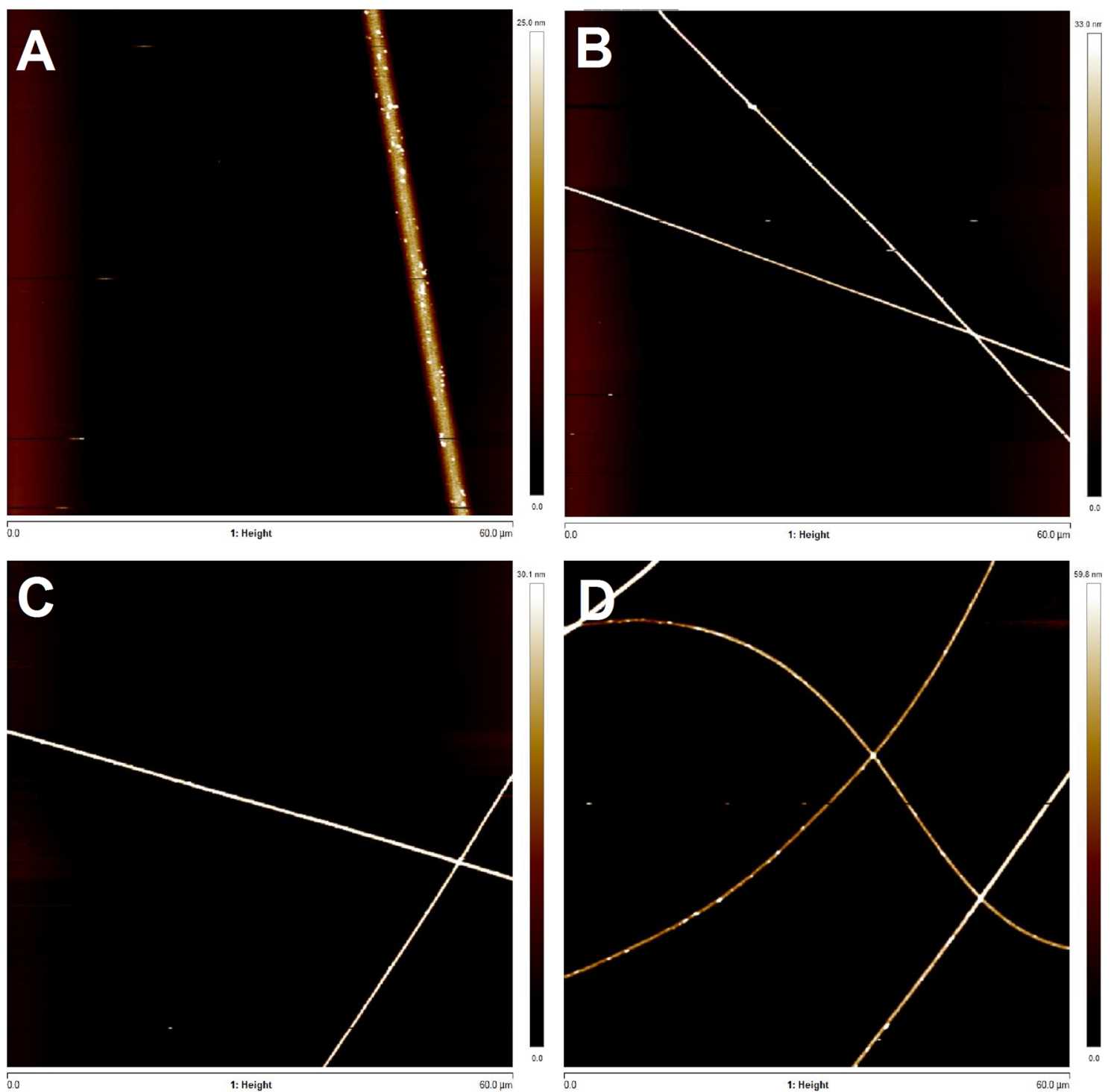

Fig. 2 AFM images of nanofibers produced under different flow rates. a $0.2, \mathbf{b} 0.4, \mathbf{c} 0.7$, and d $1.2 \mathrm{~mL} / \mathrm{h}$ 

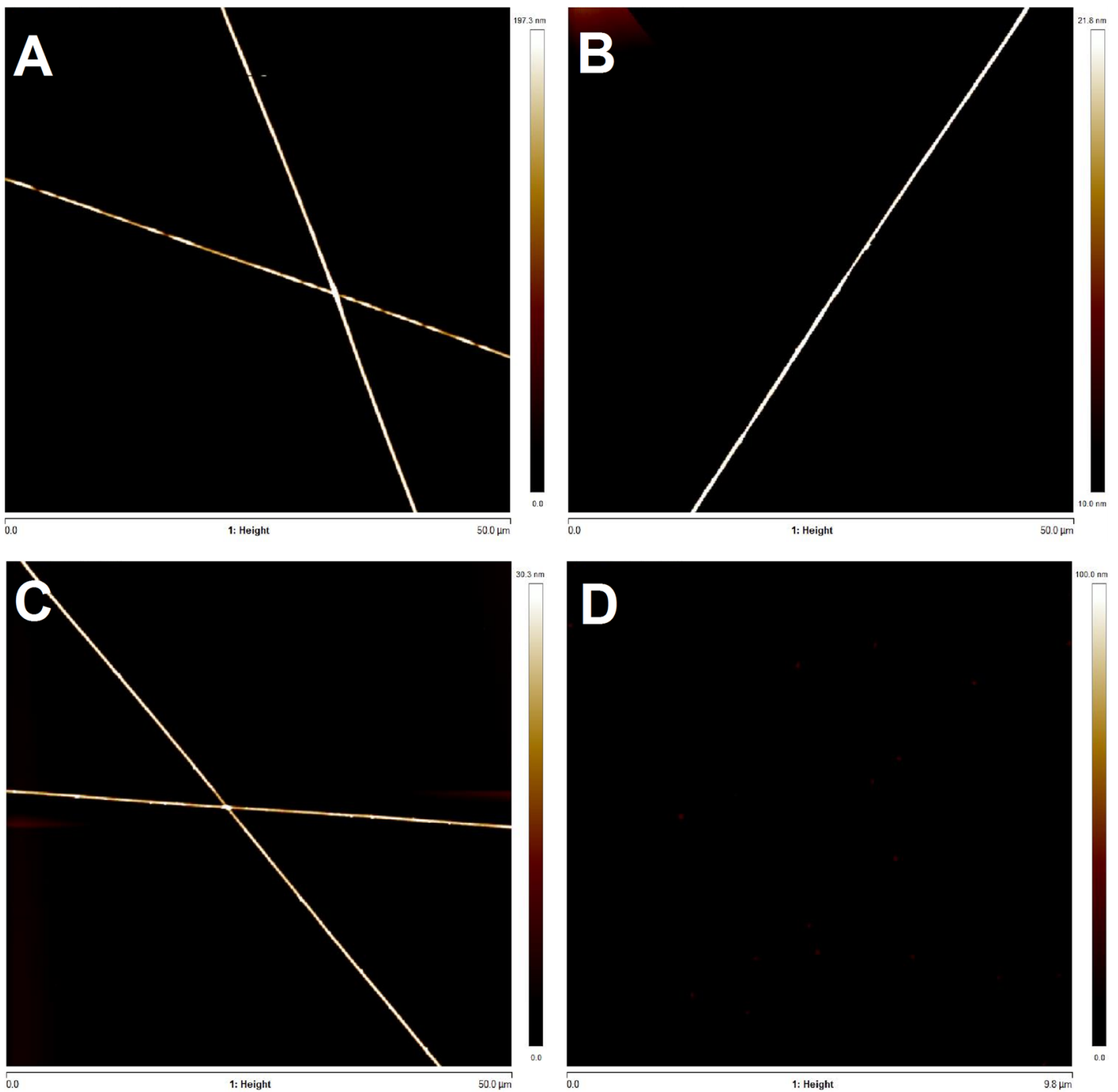

Fig. 3 AFM images of nanofibers produced under different voltages. a 10, b 14, c 18, and d $21 \mathrm{kV}$

electrospinning parameters for fabrication of the pectinbased nanofibers were optimized to a pectin:PEO ratio of 65:35 (v/v), Pluronic ${ }^{\circledR}$ F-127 concentration of $5 \%(\mathrm{w} / \mathrm{v})$, flow rate of $0.7 \mathrm{~mL} / \mathrm{h}$, and voltage of $12 \mathrm{kV}$.

\section{Effect of $\mathrm{Ca}^{2+}$ and oligochitosan on cross-liking of pectin-based nanofibers}

As shown in Fig. 4, both $\mathrm{Ca}^{2+}$ and oligochitosan can be used in aqueous solutions as cross-linkers to improve the stability of the pectin-based nanofibers. The average diameters for untreated, $\mathrm{Ca}^{2+}$-treated, and oligochitosan-treated nanofibers were $286 \pm 38,285 \pm 49$, and $219 \pm 28 \mathrm{~nm}$, respectively. The reduction in the nanofiber diameter when treated with oligochitosan might be caused by the cross-linking of pectin molecules, leading to a more compact structure, while $\mathrm{Ca}^{2+}$ treatment did not significantly change the nanofiber size. When comparing the morphology of the $\mathrm{Ca}^{2+}$-treated and oligochitosan-treated nanofibers, oligochitosan appeared to be the better choice. $\mathrm{Ca}^{2+}$ treatment caused the pectin nanofibers to aggregate and form flake-like structures (Fig. 4e), especially when the nanofiber density was high. This can be explained by different cross-linking mechanisms of $\mathrm{Ca}^{2+}$ and oligochitosan. $\mathrm{Ca}^{2+}$ cross-linking leads to the formation of macromolecular aggregates (egg-box structure) through the intermolecular chelating bonding, while oligochitosan cross-linking forms the pectin-oligochitosan electrolyte complexes (Feng et al. 2017; Zhang et al. 2016). 

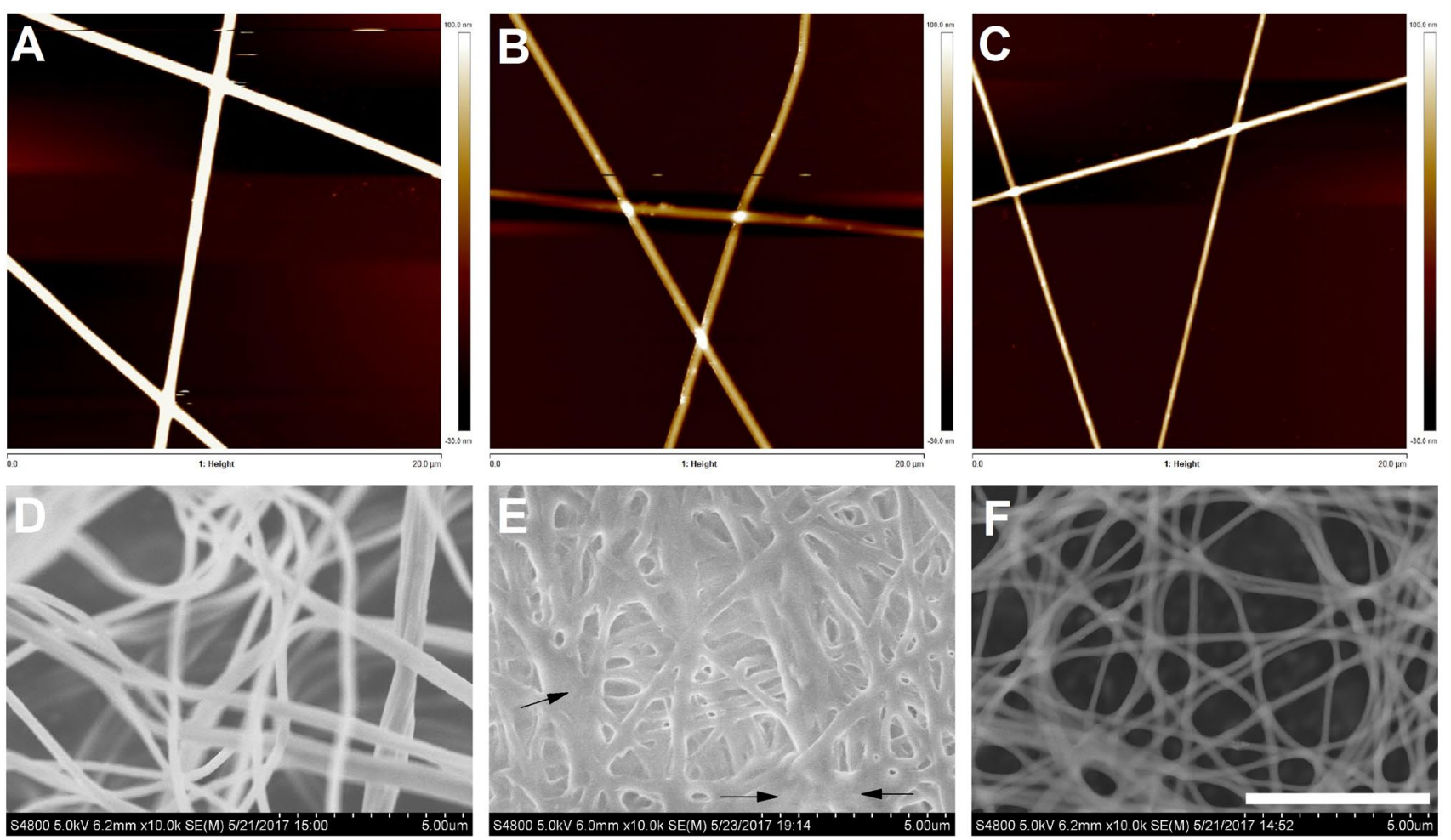

Fig. 4 AFM (top panel) and SEM (bottom panel) images of the untreated (a, d), $\mathrm{Ca}^{2+}$-treated nanofibers (b, e), and oligochitosan-treated nanofibers (c, f). Black arrows: flake-like structures. Scale bar (SEM images): $5 \mu \mathrm{m}$

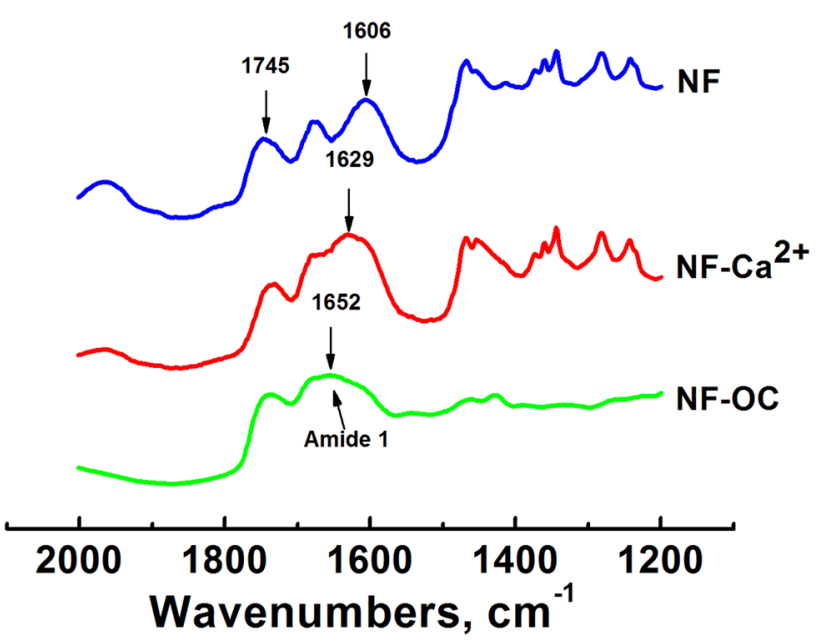

Fig. 5 FTIR spectra of untreated (NF), $\mathrm{Ca}^{2+}$-treated $\left(\mathrm{NF}-\mathrm{Ca}^{2+}\right)$, and oligochitosan-treated nanofiber (NF-OC)

\section{Chemistry and surface charge of pectin-based nanofibers}

The interaction of $\mathrm{Ca}^{2+}$ and oligochitosan with the pectinbased nanofibers can be observed using Fourier transform infrared (FTIR) spectroscopy (Crouse et al. 2015; 2016a). As shown in Fig. 5, the FTIR spectra of non-treated nanofibers and nanofibers treated with $\mathrm{Ca}^{2+}$ and oligochitosan, respectively, are shown. As described previously, the interaction of $\mathrm{Ca}^{2+}$ with the pectin-based nanofibers is demonstrated by the shift of the asymmetric stretch of the pectin carbonylate ion from 1606 to $1629 \mathrm{~cm}^{-1}$. The interaction of oligochitosan with the nanofibers is evidenced by the significant loss of intensity of the carbonylate ion. This is visualized with a weakly resolved shoulder on the amide I peak at $1652 \mathrm{~cm}^{-1}$. This interaction is also indicated by the relative increase in intensity of the peak of the pectin ester carbonyl group at $1745 \mathrm{~cm}^{-1}$. As a positive surface is preferred for cell attachment, it is critical to produce nanofibers with positive surface charges for tissue engineering applications. As shown in Fig. 6, the untreated nanofiber solution produced a negative surface charge as pectin is a polyanionic polymer. The $\mathrm{Ca}^{2+}$ treatment generated a more positive surface, but the overall charge was still negative. This is most likely due to the free carboxyl groups of pectin (Zhang et al. 2013). A positive surface was generated when treated with oligochitosan because of the free amine groups.

\section{Cytotoxicity of pectin-based nanofibers}

To assess the potential application of pectin-based nanofibers in tissue engineering, it was important to show that the nanofibers were non-cytotoxic. Mouse MC3T3-E1 


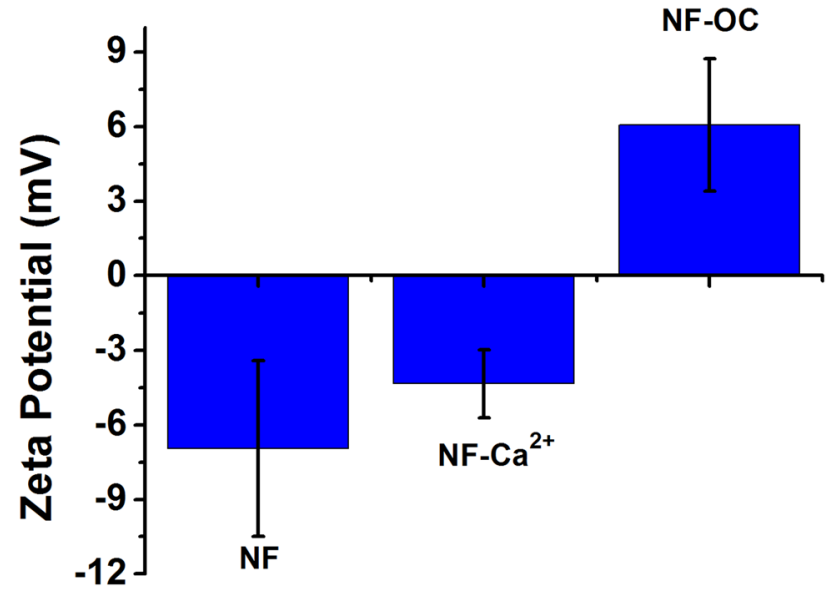

Fig. 6 Zeta potential of suspension/solution of untreated (NF), $\mathrm{Ca}^{2+}$-treated (NF-Ca ${ }^{2+}$ ), and oligochitosan-treated nanofiber (NF-OC)

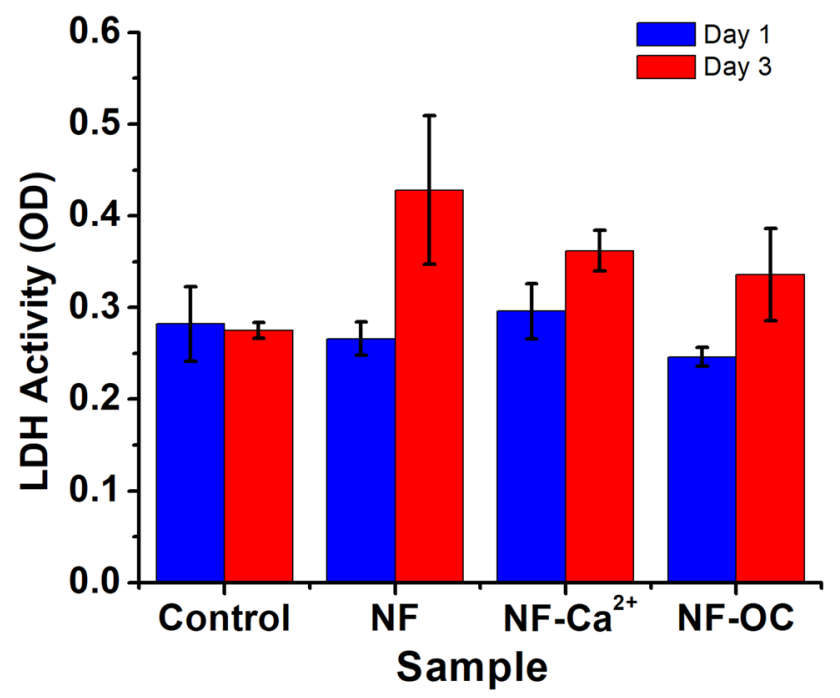

Fig. 7 Lactate dehydrogenase (LDH) activity in culture medium of MC3T3-E1 cells after incubation with untreated (NF), $\mathrm{Ca}^{2+}$-treated $\left(\mathrm{NF}-\mathrm{Ca}^{2+}\right.$ ), and oligochitosan-treated nanofiber (NF-OC), respectively. LDH activity is expressed as absorbance (OD) per milligram protein

preosteoblasts were chosen for potential bone tissue engineering application considerations. Three days after incubation, MC3T3-E1 cells cultured under different conditions all became fully confluent (Figure S1). The LDH assay was used to determine cytotoxicity. Higher LDH enzymatic activity in the cell culture supernatant indicates higher cytotoxicity which corresponds to an increased number of dead and membrane-damaged cells (Shah et al. 2017). As shown in Fig. 7, pectin-based nanofibers did not show appreciable cytotoxicity in MC3T3-E1 cells at concentrations up to $1 \mathrm{mg} / \mathrm{mL}$ for a treatment period of $72 \mathrm{~h}$, based on the LDH assay, especially for oligochitosan-treated nanofibers.

\section{Conclusion}

The parameters for producing pectin-based nanofibers were successfully optimized at a pectin:PEO ratio of $65: 35(\mathrm{v} / \mathrm{v})$, Pluronic ${ }^{\circledR}$ F-127 concentration of 5\% (w/v), flow rate of $0.7 \mathrm{~mL} / \mathrm{h}$, and voltage of $12 \mathrm{kV}$. Both $\mathrm{Ca}^{2+}$ and oligochitosan were proven to be able cross-linkers for pectin-based nanofibers to improve their stability in an aqueous solution environment. However, oligochitosan was shown to be superior when comparing the nanofiber morphology after the cross-linking treatment. Furthermore, the oligochitosan cross-linking treatment also led to a positive surface charge of nanofibers, without apparent cytotoxicity, which is preferable for tissue engineering purposes. In summary, pectin-PEO-oligochitosan nanofibers were successfully fabricated, which show great promises for biological applications.

Acknowledgements This work was partially supported by grants from NSF (EEC-1460183) and the Faculty Summer Development Grant at the Milwaukee School of Engineering (MSOE). The authors would like to recognize Mason Degeneffe (MSOE) and Marquis Henderson (North Carolina Agricultural and Technical State University) for their technical assistance.

\section{References}

Agarwal S, Wendorff JH, Greiner A (2008) Use of electrospinning technique for biomedical applications. Polymer 49:5603-5621. https://doi.org/10.1016/j.polymer.2008.09.014

Ao C, Niu Y, Zhang X, He X, Zhang W, Lu C (2017) Fabrication and characterization of electrospun cellulose/nano-hydroxyapatite nanofibers for bone tissue engineering. Int J Biol Macromol 97:568-573. https://doi.org/10.1016/j.ijbiomac.2016.12.091

Babitha S, Rachita L, Karthikeyan K, Shoba E, Janani I, Poornima B, Purna Sai K (2017) Electrospun protein nanofibers in healthcare: a review. Int J Pharm 523:52-90. https://doi.org/10.1016/j.ijpha rm.2017.03.013

Banks A, Guo X, Chen J, Kumpaty S, Zhang W (2016) Novel bioprinting method using a pectin based bioink. Technol Health Care. https://doi.org/10.3233/thc-160764

Bonino CA, Krebs MD, Saquing CD, Jeong SI, Shearer KL, Alsberg E, Khan SA (2011) Electrospinning alginate-based nanofibers: from blends to crosslinked low molecular weight alginate-only systems. Carbohydr Polym 85:111-119. https://doi.org/10.1016/j. carbpol.2011.02.002

Crouse JZ et al (2015) Development of a microscale red blood cellshaped pectin-oligochitosan hydrogel system using an electrospray-vibration method: preparation and characterization. J Appl Biomater Funct Mater 13:e326-e331. https://doi.org/10.5301/ jabfm.5000250

Cui S, Yao B, Sun X, Hu J, Zhou Y, Liu Y (2016) Reducing the content of carrier polymer in pectin nanofibers by electrospinning at low loading followed with selective washing. Mater Sci Eng C 59:885-893. https://doi.org/10.1016/j.msec.2015.10.086

Cui $\mathrm{S}$ et al (2017) Effects of pectin structure and crosslinking method on the properties of crosslinked pectin nanofibers. Carbohydr Polym 157:766-774. https://doi.org/10.1016/j.carbp ol.2016.10.052 
Feng Y, Kopplin G, Sato K, Draget KI, Vårum KM (2017) Alginate gels with a combination of calcium and chitosan oligomer mixtures as crosslinkers. Carbohyd Polym 156:490-497. https://doi. org/10.1016/j.carbpol.2016.09.006

Harvestine JN et al (2014) A novel red-blood-cell-shaped pectin-oligochitosan hydrogel system. Part Part Syst Charact 31:955-959. https://doi.org/10.1002/ppsc.201400002

Hinderer S, Layland SL, Schenke-Layland K (2016) ECM and ECMlike materials - biomaterials for applications in regenerative medicine and cancer therapy. Adv Drug Deliv Rev 97:260-269. https ://doi.org/10.1016/j.addr.2015.11.019

Ingavle GC, Leach JK (2014) Advancements in electrospinning of polymeric nanofibrous scaffolds for tissue engineering Tissue engineering Part B. Reviews 20:277-293. https://doi.org/10.1089/ ten.TEB.2013.0276

Ko JH, Kim YH, Jeong SH, Lee S, Park S-N, Shim IK, Kim SC (2015) Collagen esterification enhances the function and survival of pancreatic $\beta$ cells in 2D and 3D culture systems. Biochem Biophys Res Commun 463:1084-1090. https://doi.org/10.1016/j. bbrc.2015.06.062

Limongi T et al (2016) Fabrication and applications of micro/nanostructured devices for tissue engineering. Nano Micro Lett 9:1. https://doi.org/10.1007/s40820-016-0103-7

Mortimer CJ, Wright CJ (2017) The fabrication of iron oxide nanoparticle-nanofiber composites by electrospinning and their applications in tissue engineering. Biotechnol J. https://doi.org/10.1002/ biot. 201600693

Naahidi S et al (2017) Biocompatibility of hydrogel-based scaffolds for tissue engineering applications. Biotechnol Adv 35:530-544. https://doi.org/10.1016/j.biotechadv.2017.05.006

Ngadiman NHA, Noordin MY, Idris A, Kurniawan D (2017) A review of evolution of electrospun tissue engineering scaffold: from two dimensions to three dimensions. Proc Inst Mech Eng Part H J Eng Med 231:597-616. https://doi.org/10.1177/0954411917699021

Noreen A et al (2017) Pectins functionalized biomaterials; a new viable approach for biomedical applications: a review. Int $\mathrm{J}$
Biol Macromol 101:254-272. https://doi.org/10.1016/j.ijbio mac.2017.03.029

Shah M, Bourner L, Ali S, Al-Enazy S, Rytting E (2017) Cytotoxicity of endocytosis and efflux inhibitors in the BeWo cell line. J Pharm Res Int. https://doi.org/10.9734/jpri/2017/34606

Song W et al (2011) Cyclodextrin-erythromycin complexes as a drug delivery device for orthopedic application. Int J Nanomed 6:31733186. https://doi.org/10.2147/IJN.S23530

Stevens MM, George JH (2005) Exploring and engineering the cell surface interface. Science 310:1135-1138. https://doi.org/10.1126/ science. 1106587

Suga T, Osada S, Narita T, Oishi Y, Kodama H (2015) Promotion of cell adhesion by low-molecular-weight hydrogel by Lys based amphiphile. Mater Sci Eng C 47:345-350. https://doi. org/10.1016/j.msec.2014.11.032

Zhang W et al (2013) A novel core-shell microcapsule for encapsulation and 3D culture of embryonic stem cells. J Mater Chem B Mater Biol Med 2013:1002-1009. https://doi.org/10.1039/c2tb0 0058j

Zhang W et al (2016a) Design of artificial red blood cells using polymeric hydrogel microcapsules: hydrogel stability improvement and polymer selection. Int J Artif Organs. https://doi.org/10.5301/ ijao.5000532

Zhang W et al (2016b) Novel pectin-based carriers for colonic drug delivery. Pharm Dev Technol 21:127-130. https://doi. org/10.3109/10837450.2014.965327

Zhang W, Choi JK, He X (2017) Engineering microvascularized 3D tissue using alginate-chitosan microcapsules. J Biomater Tissue Eng 7:170-173. https://doi.org/10.1166/jbt.2017.1547

Publisher's Note Springer Nature remains neutral with regard to jurisdictional claims in published maps and institutional affiliations. 